\title{
Transoesophageal echocardiography: What a neuroanaesthesiologist should know?
}

\author{
Minati Choudhury
}

\begin{abstract}
Transoesophageal echocardiography (TEE) is a semi invasive imaging modality rapidly gained credence and popularity in the cardiothoracic centers worldwide by mid 1990s. It has also been found to be useful in some noncardiac surgical procedures, in particular in the management of neurosurgical patients and haemodynamically unstable patients in intensive care units (ICUs). The principal goal of basic transoesophageal echocardiographic examination encompass a broad range of anatomic imaging including the diagnosis of air embolism, causes of haemodynamic instability, ventricular size and function, volume status, and complications from invasive procedures, as well as the clinical impact or etiology of pulmonary dysfunction in ICU.TEE is relatively cheap and semi-invasive, but it should not be used as a stand-alone device but as a tool which provides data in addition to the data acquired from other forms of monitoring. The establishment of TEE in perioperative neuro anaesthetic care though recent, may result in a significant change in the role of the anaesthetsiologist who, using TEE can provide new information which may change the course and the outcome of surgical procedures.
\end{abstract}

Key words: Monitoring, neuroanaesthesia, transoesophageal echocardiography

\section{INTRODUCTION}

Since its introduction in cardiac operating room (OR) in 1990, transoesophageal echocardiography (TEE) had a natural progression to the non-cardiac operating rooms in the management of life-threatening haemodynamic events. However, there is no randomized control trial evaluating the utility of TEE in the aforementioned situation. It is now recognized as an excellent perioperative diagnostic tool rather than a simple monitoring device because of its utility is unquestionable in life threatening situations. ${ }^{[1-3]}$ Early diagnosis and treatment of venous air embolism and major cardiovascular instability in OR as well as in intensive care unit (ICU) is crucial in enhancing survival

\begin{tabular}{|l|l|}
\hline \multicolumn{2}{|c|}{ Access this article online } \\
\hline Quick Response Code: & Website: \\
\hline & www.jnaccjournal.org \\
\hline & \\
\hline
\end{tabular}

and limiting the associated morbidity and mortality in patients undergoing neurosurgery. Few authors investigated the use of TEE in neurosurgical setting and the reports are mainly restricted to life-threatening venous air embolism (VAE) ${ }^{[4]}$ Hence, it is useful to think of categories of indications of TEE in neurosurgical and neuroanaesthesia settings and then evaluate the impact of TEE in those indications.

In this review, the basics of TEE, the relevant TEE views for a neuroanaesthesiologist, skill requirement and evidence on use of TEE in perioperative neurosurgical setting are discussed.

\section{PRINCIPLES OF ECHOCARDIOGRAPHY}

In echocardiography the heart and great vessels are insonated with ultrasound, which is sound above human audible range $(20,000 \mathrm{~Hz})$. The ultrasound is sent into thoracic cavity and partially reflected by the cardiac structures. From these reflections, distance, velocity and density of the objects under examination are derived. These waves are characterized by their wave length, frequency and velocity. In TEE, ultrasound beam is a continuous or intermittent chain

Department of Cardiac Anaesthesia, Cardiothoracic Sciences Centre, All India Institute of Medical Sciences, New Delhi, India

Address for correspondence:

Dr. Minati Choudhury, Department of Cardiac Anaesthesia, Cardiothoracic Sciences Centre, All India Institute of Medical Sciences,

New Delhi - 110 029, India. E-mail: minatichoudhury2002@yahoo.co.in 
of sound waves emitted by a transducer consists of piezoelectric crystals e.g. barium titanate, lead metaniobate or lead zirconate titanate. The transducers work by piezo-electric effect (from Greek word, Piezein, to press tight), where by certain crystals deform when strong electric fields are imposed upon them and reciprocally, will generate a voltage when deformed mechanically. Commonly, a short ultrasound signal is emitted from the piezo electric crystal, which is directed to the area to be imaged. After ultrasound wave formation, the crystal 'listens' for the returning echoes for a given period and then pauses before repeating the cycle. The reflected ultrasound wave return to those piezo-electric crystals, are converted into electrical signals, which may be processed and displayed in the screen. The amplitude or strength of the returning signal provides information about the characteristics of the tissue examined. ${ }^{[3]}$

In the OR as well as in ICU, TEE is commonly used to assess cardiac anatomy and function, evaluation of thoracic aorta, detection of intra cardiac defects, evaluation of pericardial effusions and tamponade, detection of intracardiac air, clot or masses (may be responsible for arrhythmia and haemodynamic instability, assessment of ventricular function and not the last, the evaluation of myocardial ischaemia. These are the few of the problems an anaesthesiologist/intensivist encounter during management of a patient that can be rapidly diagnosed with the aid of TEE.

\section{COMPONENTS OF A TEE UNIT AND INSTRUMENT CONTROLS FOR IMAGING}

A typical TEE unit consists of two components: The transducer (probe) [Figure 1], the display and the recording unit (Echocardiographic machine) [Figure 2]. The present day TEE probe is usually multiplane and better described as a modified gastroscope with motor-controlled ultrasonic transducer at the tip which functions both as the transmitter and receiver of ultrasonic waves. The shaft of the probe may be advanced into or withdrawn from the oesophagus and turned to right (clock wise) or left (anti-clock wise). The tip of the probe may be antiflexed or retroflexed by rotating the large control wheel on the handle of the probe. Rotating the small control wheel flexes the tip of the probe to the right or left. The movements are usually described with the reference to the echocardiogapher standing at the patients head looking forward the patient's feet. Rotation of the transducer refers to the movement of sector scan from $0-180^{\circ}$ [Figure 3]. The TEE probe is available in three sizes i.e. adult (suitable for patients weighing more than $25 \mathrm{kgs})$, paediatric $(5-25 \mathrm{kgs})$ and neonatal (2.5-5 kgs). The term 'short axis' and long axis' are used while acquiring/describing a TEE image. 'Short axis'

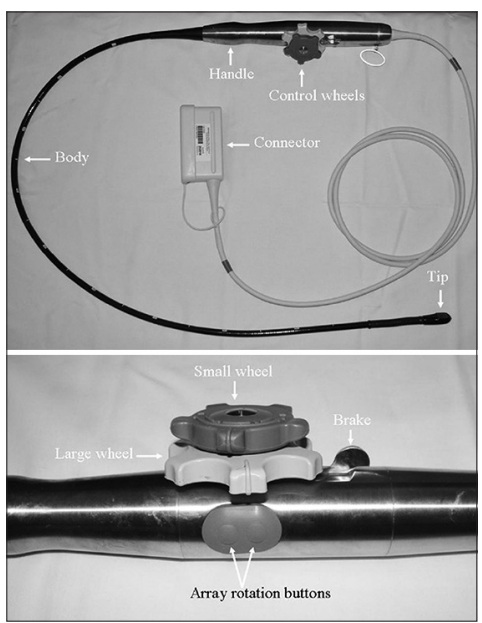

Figure 1: Trans esophageal echocardiography probe showing different parts

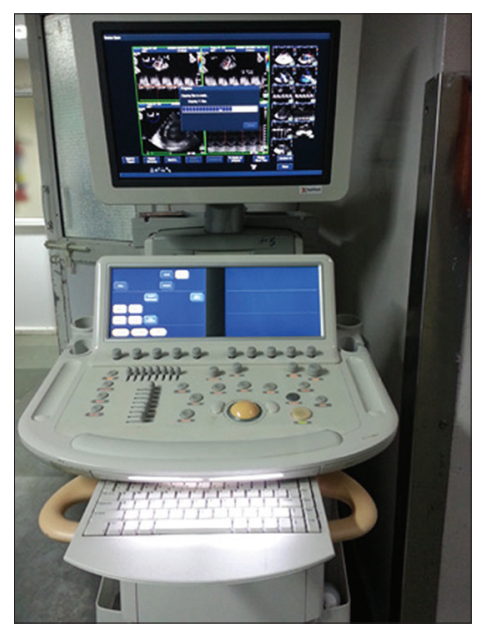

Figure 2: Echocardiograph machine showing the image screen and control knobs

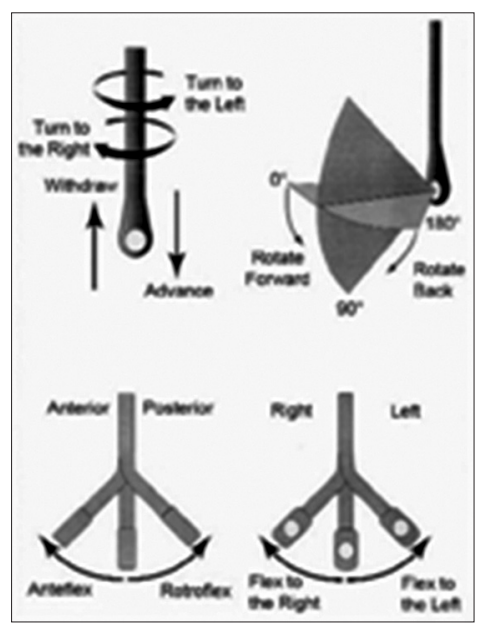

Figure 3: Angle of rotation of TEE probe

refers to an image plane perpendicular to the structure of interest and 'long axis' refers to an image plane parallel to the length of structure of interest. 
Images are collected by placing the probe at four depths: Upper oesophagus (20-30 cm), mid oesophagus $(30-40 \mathrm{~cm})$, transgastirc $40-45 \mathrm{~cm})$ and deep transgastric $(45-50 \mathrm{~cm})$. In general, great majority of the images are obtained at mid oesophagus and transgastric level. Mid-esophageal views are mainly used to detect the presence of any intracardiac shunt and air where as the transgastric views are meant to evaluate ventricular function. Upper esophageal views are mostly utilized for assessment of aortic atheroma and aneurysm. Elderly patients with carotid stenosis and history of stroke can be benefited from this assessment.
The TEE machine consists of different control knobs which are essential to acquire an optimum image [Table 1]. This review describes the views relevant for the management of a neurosurgical patient [Table 2]. However, for the basic knowledge regarding all the views the reader can refer elsewhere..$^{[1-3]}$

\section{TERMINOLOGIES ONE SHOULD KNOW}

The transducer emits a main beam up to a certain distance from the face known as near field length. Beyond the near field length the beam diverges into a conical

\section{Table 1: Instrument controls for imaging}

\begin{tabular}{|c|c|}
\hline Control knobs & Function \\
\hline Transmit power & $\begin{array}{l}\text { Adjusts the amount of acoustic energy delivered to the tissues. This setting should be kept as low as } \\
\text { possible to produce good image quality }\end{array}$ \\
\hline Receiver gain & $\begin{array}{l}\text { Adjusts the overall sensitivity of the ultrasound system to the received echoes and should be set as high } \\
\text { as possible }\end{array}$ \\
\hline $\begin{array}{l}\text { Time gain } \\
\text { compensation }\end{array}$ & $\begin{array}{l}\text { As an ultrasound beam propagates through a single tissue, it progressively diminishes its amplitude } \\
\text { owing to internal frictional heating, reflection and scattering from in homogeneities within the tissues. } \\
\text { This phenomenon is called 'attenuation'. The retuned signal strength from any given tissue interface } \\
\text { will vary with the amount of overlying tissue and resultant signal attenuation. In order to make } \\
\text { tissue interfaces of the same reflectivity have the same appearance anywhere in the image, 'time-gain } \\
\text { compensation' is employed. Several slider type controls adjusts the relative sensitivity of the system to } \\
\text { received echoes from a particular band depths. These controls should be adjusted frequently to optimize } \\
\text { the appearance of individual image }\end{array}$ \\
\hline $\begin{array}{l}\text { Lateral gain } \\
\text { compensation }\end{array}$ & $\begin{array}{l}\text { Manipulation of these knobs compensate 'image drop out' where the ultrasound beam strikes the } \\
\text { endocardial border obliquely }\end{array}$ \\
\hline Depth & $\begin{array}{l}\text { Normally, depth should be high enough to include whole heart in a particular view. e.g., Quality of } \\
\text { 4-Chamber view can be defined if the left atrium is completely visualized }\end{array}$ \\
\hline Presets & $\begin{array}{l}\text { Machine settings can be saved as presets. For different transducers, patients (e.g., adult, paediatric) and } \\
\text { structures different presets can be created }\end{array}$ \\
\hline Output power & $\begin{array}{l}\text { This determines the energy transmitted by the transducer. Normally power is set up on maximum level } \\
\text { to improve signal to noise ratio }\end{array}$ \\
\hline Compression & $\begin{array}{l}\text { Changing this knob setting alters the number of grey shades in the image. The lower the compression } \\
\text { the less the number of shades with the consequence of more contrast appearance }\end{array}$ \\
\hline Reject & This control is used to eliminate low level artificial signals displayed in the image as noise \\
\hline Sector width & Wide imaging width gives better overview of cardiac structures, especially in patients with enlarged hearts \\
\hline Focus & Focus control optimizes the lateral resolution at a given depth \\
\hline Zoom & $\begin{array}{l}\text { This control enlarges the pixels within a selected region of interest and enables the operator to appreciate } \\
\text { existing image detail better }\end{array}$ \\
\hline Freeze & $\begin{array}{l}\text { Pressing this control puts the system in a standby state, stops ultrasonic transmission and retain in } \\
\text { digital memory a sequence of the immediately preceding image frame and allow the operator to study } \\
\text { the image in detail by scrolling through }\end{array}$ \\
\hline Trackball & $\begin{array}{l}\text { It is a pointing device that contains a movable ball rotated with the fingers similar to using a mouse on the } \\
\text { computer. It is used for moving Doppler boxes to the desired location and for measuring and annotating }\end{array}$ \\
\hline $\begin{array}{l}\text { Brightness, } \\
\text { contrast, } \\
\text { colourization } \\
\text { and grey scale }\end{array}$ & $\begin{array}{l}\text { These controls are used to enhance contrast resolution to enable the eye to distinguish better between } \\
\text { nearby echoes in the image differing only slightly in their signal strength. Colourization is used by } \\
\text { taking advantage of human visual system ability to distinguish certain colour variation than grey levels. } \\
\text { These controls should be adjusted to produce the most pleasing and diagnostically useful image }\end{array}$ \\
\hline 2-D gain & Adjustment of this knob makes the chambers black, while tissues remain white/grey \\
\hline Colour gain & This is adjusted to a level below that which produces background noise and speckling \\
\hline Sector depth & This knob optimizes the view of the structures being assessed and usually kept between $6-16 \mathrm{~cm}$ \\
\hline
\end{tabular}


Table 2: Views of interest for neurosurgical setting

\begin{tabular}{|c|c|c|c|}
\hline View & $\begin{array}{l}\text { Transducer level and probe } \\
\text { manipulation }\end{array}$ & Structures visualized & Utility \\
\hline $\begin{array}{l}\text { LV basal SX } \\
0^{\circ} \\
\text { Sector depth: } 12 \mathrm{~cm}\end{array}$ & $\begin{array}{l}\text { Transgastric } \\
\text { By turning the shaft of the probe to } \\
\text { right SX view of RV can be seen which } \\
\text { has a crescent shape and thickness } \\
\text { half of that of LV }\end{array}$ & $\begin{array}{l}\mathrm{LV} \text { in SX } \\
\mathrm{RV} \text { in SX (Figure 4) }\end{array}$ & $\begin{array}{l}\text { Monitoring of global } \\
\text { as well as regional LV } \\
\text { function } \\
\text { Preload assessment }\end{array}$ \\
\hline $\begin{array}{l}\text { Mid papillary view } \\
0^{\circ} \\
\text { Sector depth: } 12 \mathrm{~cm}\end{array}$ & $\begin{array}{l}\text { Transgastric } \\
\text { Slight advancement and antiflexion } \\
\text { of the probe from basal SX view } \\
\text { demonstrates papillary muscles of LV. } \\
\text { By turning the shaft of the probe to } \\
\text { right, SX view of the RV can be seen }\end{array}$ & $\begin{array}{l}\text { LV in SX with papillary } \\
\text { muscles (Figure 5) }\end{array}$ & $\begin{array}{l}\text { Monitoring of LV } \\
\text { function } \\
\text { Volume status of the } \\
\text { patient } \\
\text { LV regional wall } \\
\text { motion abnormality }\end{array}$ \\
\hline $\begin{array}{l}\text { Four chamber view } \\
0-20^{\circ} \\
\text { Sector Depth: } 12-14 \mathrm{~cm} \\
\text { Slight retroflexion }\end{array}$ & Mid oesophagus & $\begin{array}{l}\mathrm{LV}, \mathrm{RV}, \mathrm{LA}, \mathrm{RA}, \mathrm{MV}, \mathrm{TV}, \\
\text { IAS and IVS } \\
\text { The septal wall of LV is seen } \\
\text { in the left and lateral wall of } \\
\mathrm{LV} \text { on right. The RV free wall } \\
\text { is seen on the left and septal } \\
\text { wall on the right. (Figure 6) }\end{array}$ & $\begin{array}{l}\text { Chamber enlargement } \\
\text { Valve function } \\
\text { Detection of } \\
\text { intracardiac air/mass } \\
\text { Detection of atrial } \\
\text { septal defect }\end{array}$ \\
\hline $\begin{array}{l}\text { Two chamber view } \\
80-100^{\circ} \\
\text { Sector Depth: } 12-14 \mathrm{~cm}\end{array}$ & $\begin{array}{l}\text { Mid oesophagus } \\
\text { Rotate the probe from } 4 \text {-camber view } \\
\text { till the coronary sinus (short axis) } \\
\text { appears on left and left atrial } \\
\text { appendage on right }\end{array}$ & $\begin{array}{l}\text { LAA, MV and LV apex } \\
\text { (Figure 7) }\end{array}$ & $\begin{array}{l}\text { LAA mass/thrombus } \\
\text { Function of mitral } \\
\text { valve and LV }\end{array}$ \\
\hline $\begin{array}{l}\text { AV long axis view } \\
25-54^{\circ} \\
\text { Sector deapth: } 10-12 \mathrm{~cm}\end{array}$ & $\begin{array}{l}\text { Mid oesophagus } \\
\text { Slight withdraw and rotate the probe } \\
\text { from } 4 \text {-camber view }\end{array}$ & $\begin{array}{l}\text { AV, LVOTO, ascending } \\
\text { aorta (Figure 8) }\end{array}$ & $\begin{array}{l}\text { Aortic valve pathology } \\
\text { Air in LA and } \\
\text { coronaries }\end{array}$ \\
\hline $\begin{array}{l}\text { Bicaval view } \\
90-110^{\circ} \\
\text { Sector deapth: } 8-10 \mathrm{~cm}\end{array}$ & $\begin{array}{l}\text { Mid oesophagus } \\
\text { Slight turning of the probe to right } \\
\text { from AV long axis view }\end{array}$ & $\begin{array}{l}\text { LA, RA, SVC, IVC, } \\
\text { IAS (Figure 9) }\end{array}$ & $\begin{array}{l}\text { Diagnosis of PFO, } \\
\text { ASD } \\
\text { RA mass }\end{array}$ \\
\hline $\begin{array}{l}\text { Descending aortic short } \\
\text { axis view } \\
0^{\circ} \\
\text { Sector deapth: } 6 \mathrm{~cm}\end{array}$ & $\begin{array}{l}\text { Upper oesophagus } \\
\text { Withdraw and turn the probe to left } \\
\text { from ME -4-chamber view till the } \\
\text { circular short axis view of DTA is seen } \\
\text { on upper part of screen }\end{array}$ & (Figure 10) & $\begin{array}{l}\text { Aortic atheroma and } \\
\text { aortic dissection }\end{array}$ \\
\hline $\begin{array}{l}\text { Descending aortic long } \\
\text { axis view } \\
90^{\circ} \\
\text { Sector deapth: } 6 \mathrm{~cm}\end{array}$ & Upper oesophagus & (Figure 11) & $\begin{array}{l}\text { Aortic atheroma and } \\
\text { aortic dissection }\end{array}$ \\
\hline
\end{tabular}

SX: Short axis, LA: Left atrium, LV: Left ventricle, LVOT: Left ventricle outflow tract, AV: Aortic valve, RA: Right atrium, RV: Right ventricle, PV: Pulmonary valve, RVOT: Right ventricular outflow tract, LAA: Left atrial appendage, PV: Pulmonary vein, PA: Pulmonary artery, PFO: Patent foramen ovale, ASD: Atrial septal defect, SVC: Superior venacava, IVC: Inferior vena cava, ASD: Atrial septal defect

pattern (far field), with an angle determined by the ratio of the wave length to the transducer diameter [Figure 12]. These are the secondary beams (side lobe) emitted by the transducer that are angled obliquely to the centre of main beam. Side lobes are much weaker than the main beam, but when encounter strong reflectors they can generate fade targets (side lobe artifacts) and thereby produce multiple images from a single target.

\section{Mechanical sector scanner}

For making of a 2-D image, transducer beam is swept over a region of interest in a fan-like fashion which is called a 'mechanical sector scanner'.

\section{Resolution}

'Resolution' is a measure of systems' ability to distinguish echoes from different sources that are close to each other in time, space or return signal strength (known as temporal, spatial and contrast resolution, respectively).

\section{Aliasing}

It refers to the distortion or artifact those results when signal reconstructed from samples is different from the original continuous signal and should be avoided with proper knob control. 


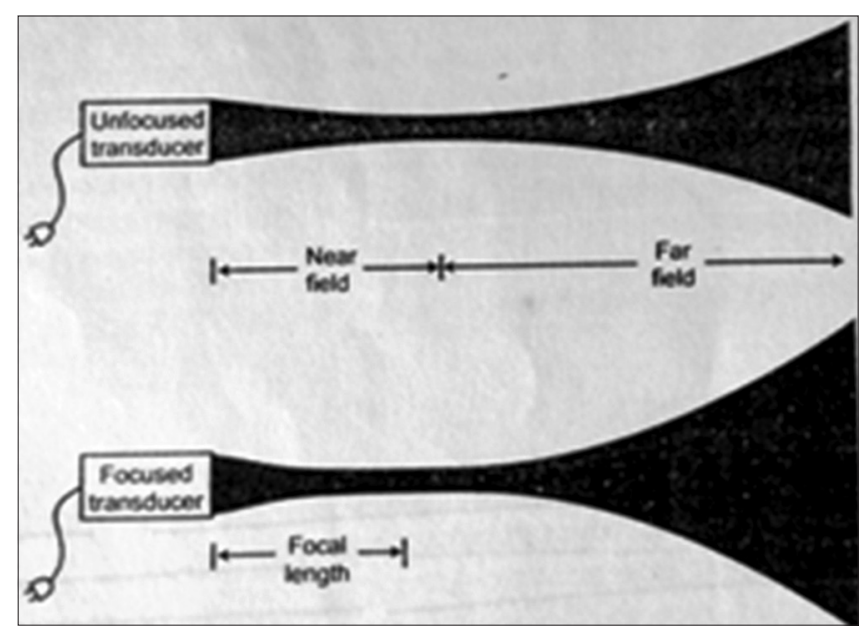

Figure 4: The beam from a transducer showing near field and far field

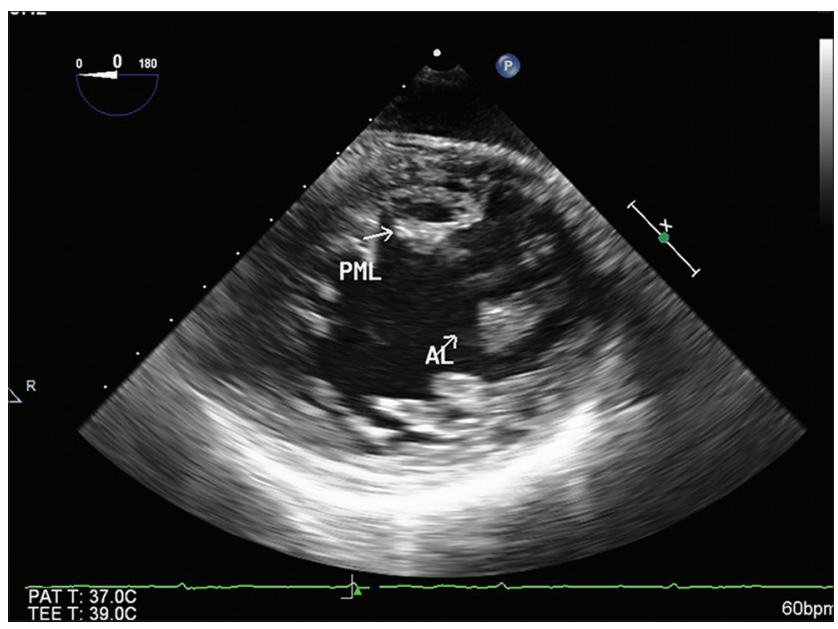

Figure 6: Transgastric LV mid papillary view

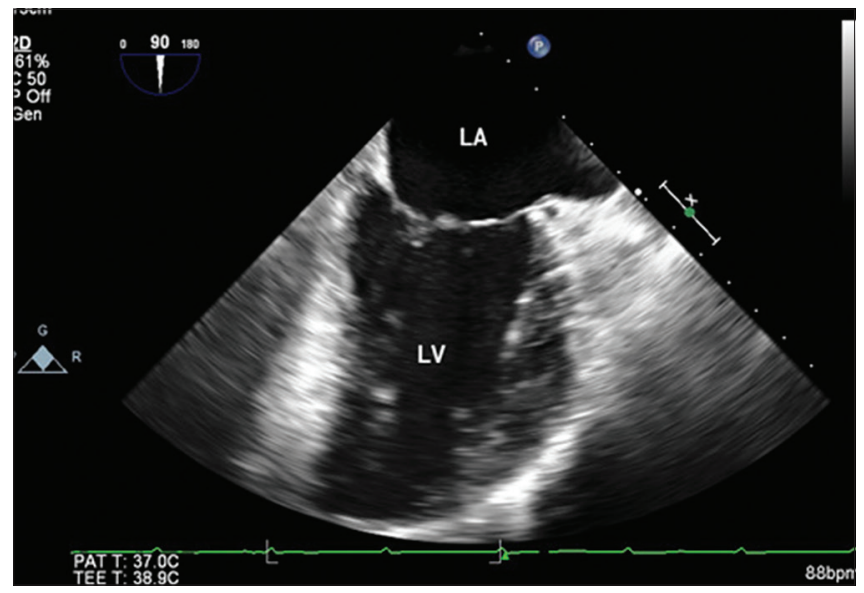

Figure 8: Mid esophageal LV 2-chamber view

\section{Frame rate}

It is the frequency rate at which an imaging device produces unique consecutive images called 'frames'. It is expressed as frames/second or Hertz (Hz). In moving subjects (blood/heart) and during quantitative measurement, whether based on the Doppler Effect or

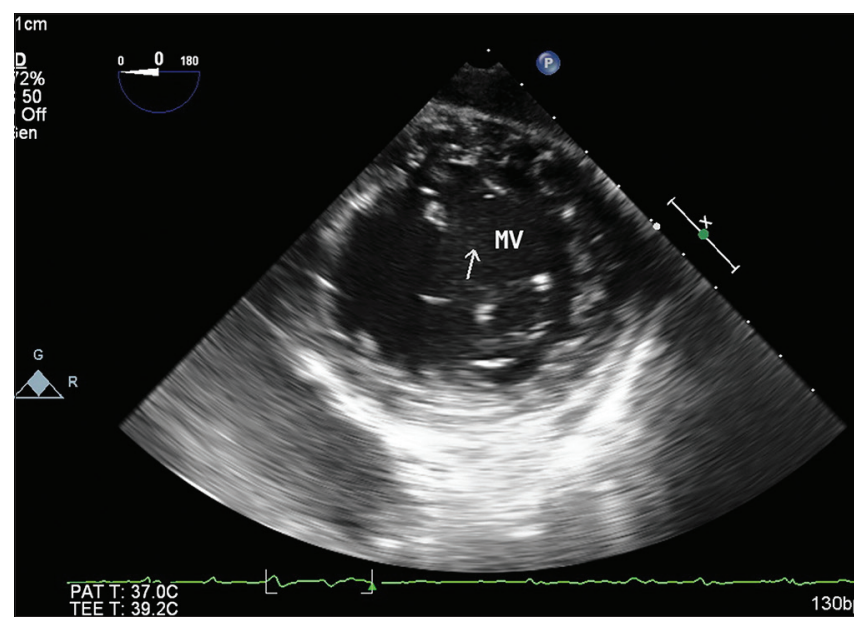

Figure 5: Transgastric LV short axis view showing mitral valve and left ventricular cavity

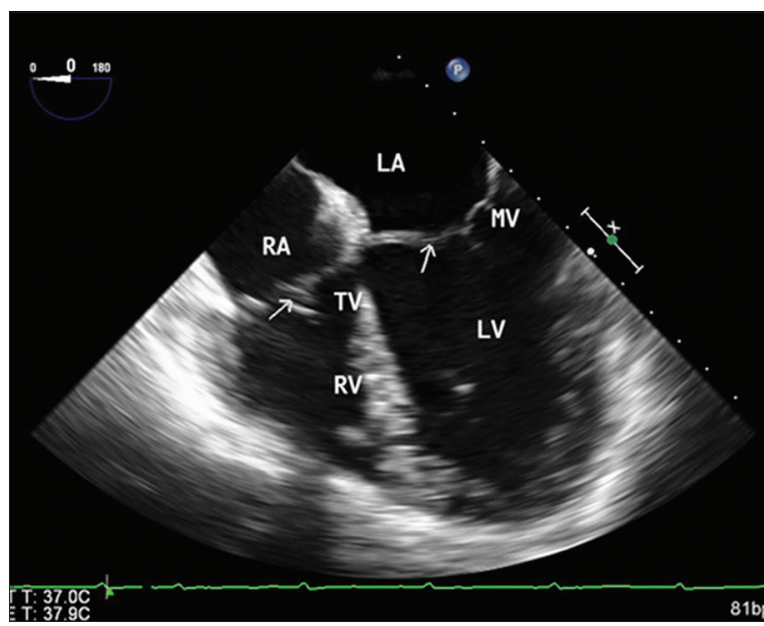

Figure 7: Mid esophageal 4-chamber view

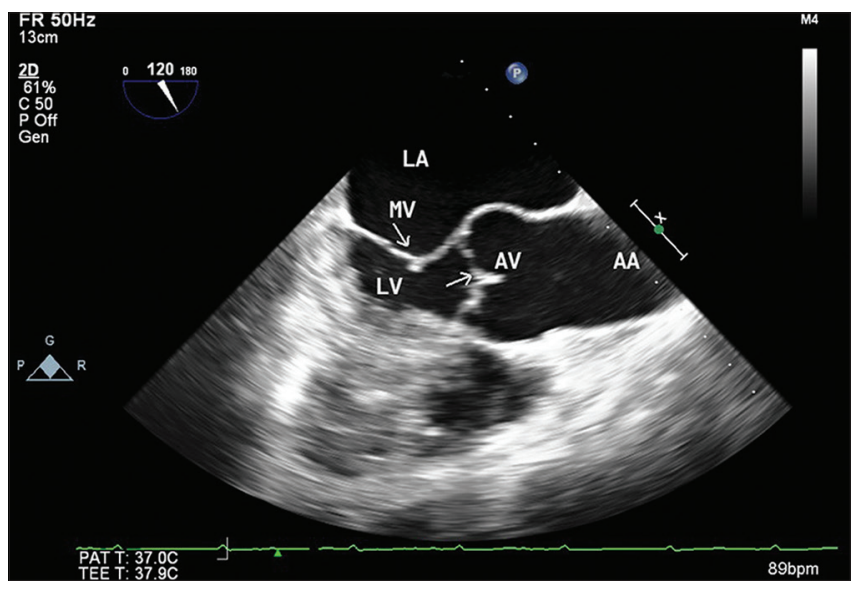

Figure 9: Mid esophageal aortic valve long axis view

2D B-mode data, sufficient frame rate is important to avoid under sampling.

\section{Nyquist limit}

It gives us a theoretical limit to what rate we have to sample a signal that contains data at a certain maximal 
limit. Sampling below this limit can give rise to inadequate sampling or corruption of the image known as Aliases.

\section{Type of echo images}

A mode (amplitude mode) image

It measures only the depth of the tissue (single dimensional) is of limited clinical usefulness.

\section{M mode (motion mode)}

$\mathrm{M}$ mode has an advantage of imaging the moving structures (heart wall, valve leaflets). In M mode imaging, the amplitude of returning echoes is plotted as the brightness along vertical lines drawn for each transmitted echo pulse. The echo pulses are repeated at rates of thousands per second and a raster of vertical lines, scanned along the same path, is drawn from right to left at speeds compatible to ECG recording $(25-100 \mathrm{~mm} / \mathrm{s})$.

\section{B mode (brightness mode) or 2-D mode}

In this mode, as ultrasound waves penetrate tissues of differentacousticimpedancealong the path of transmission, some are reflected back to the transducer (echo signals) and some continue to penetrate deeper. The returned echo signals are processed and combined to generate an image. This mode allows the measurement of a plane of tissue (both depth and width) in real time and thereby makes it easier to appreciate the relationship between various anatomic structures.

\section{Doppler echocardiography}

This allows evaluation of blood flow patterns, direction and velocity; thus permits documentation and quantification of valvular insufficiency or stenosis, presence of cardiac shunts, estimation of blood flow and cardiac output. Calculation of blood flow velocity is possible when the flow is parallel to the angle of ultrasound beam.

\section{Two types of Doppler echocardiography are in clinical use \\ Pulsed Wave Doppler}

PW allows us to measure blood velocities at a single point (designated as sample volume). It requires the ultrasound probe to send out a pulsed signal to a certain depth (chosen by the operator) and then to listen for the reflected frequency shift from that particular depth. Subsequently, the computer calculates the velocity of flow at the chosen point.

\section{Continuous Wave Doppler}

$\mathrm{CW}$ allows us to measure blood velocities along an entire line of interrogation. It requires the probe to continuously send out pulses of ultrasound along a line and continuously listen for the multitude of reflected frequency shifts that are coming back. Because of this, we are able to use continuous wave Doppler to pick up very high velocity flows, ones which PW cannot accurately measure. The major disadvantage with CW Doppler is that sampling of blood flow velocity and direction occurs all along the ultrasound beam, not in a specific area.

\section{Color flow Doppler echocardiography}

Doppler colour flow imaging is colour-coded for direction and velocity of blood flow. Most systems code blood flow towards the transducer as red and flow away as blue. Differences in relative velocity of flow can be accentuated, and the presence of multiple velocities and directions of flow (turbulences) can be indicated by different maps which utilize variations in brightness and colour.

\section{Contraindications and complications}

The expansion of TEE carries with it not only the benefits of rapid and highly effective investigation but also the risk associated with the procedure itself and therefore must be performed only by qualified physicians. The possible contraindications and complications associated with this technology are described [Table 3].

\section{Steps for insertion of a TEE probe in an}

anaesthetized individual

- Mouth is examined for abnormalities and loose teeth

- An informed consent from the patient is obtained prior to the procedure

- Decompression of stomach by a nasogastric tube

- A bite-guard is inserted to prevent injury to the probe by the patient's teeth

- Lubrication of the probe with jelly

- Displace the mandible anteriorly and advance the probe gently in the midline; if blind insertion of

Table 3: Contraindications and complications

\begin{tabular}{|c|c|}
\hline Contraindications & Complications \\
\hline Absolute & Dental injury \\
\hline $\begin{array}{l}\text { Oesophageal strictures, } \\
\text { tumours, diverticula }\end{array}$ & Vocal cord damage \\
\hline Scleroderma of esophagus & Thermal injury \\
\hline $\begin{array}{l}\text { Acute upper } \\
\text { gastrointestinal bleeding }\end{array}$ & $\begin{array}{l}\text { Gastrointestinal tract (GI) tract } \\
\text { bleeding }\end{array}$ \\
\hline Perforated viscus & $\begin{array}{l}\text { Oesophageal perforation/ } \\
\text { bleeding }\end{array}$ \\
\hline $\begin{array}{l}\text { Recent upper } \\
\text { gastrointestinal surgery }\end{array}$ & Arrhythmia \\
\hline Oesophageal varices & Laryngeal palsy \\
\hline Relative & Dysphagia \\
\hline Atlanto axial joint disease & Accidental tracheal extubation \\
\hline $\begin{array}{l}\text { Prior irradiation to the } \\
\text { chest }\end{array}$ & $\begin{array}{l}\text { Airway obstruction and } \\
\text { increased ventilatory pressure }\end{array}$ \\
\hline Hiatal hernia & Distraction from anaesthetic care \\
\hline
\end{tabular}




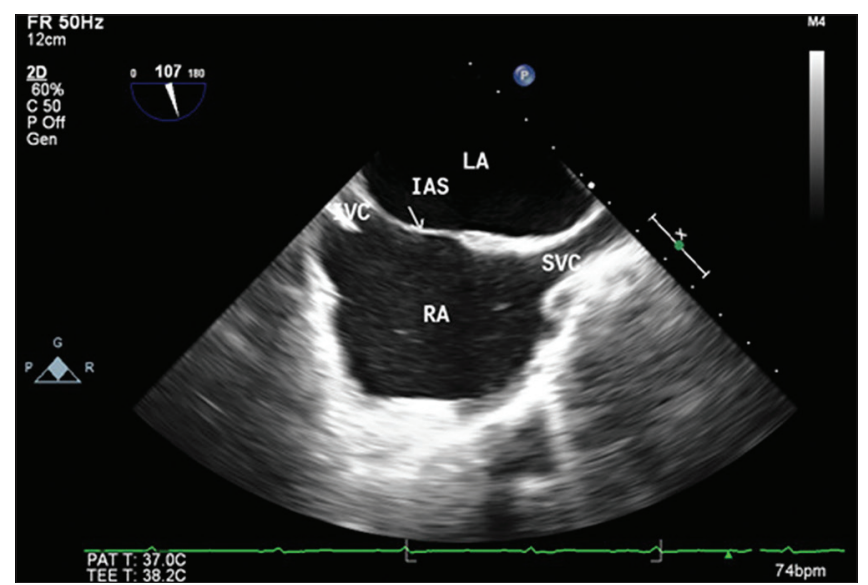

Figure 10: Mid esophageal bicaval view

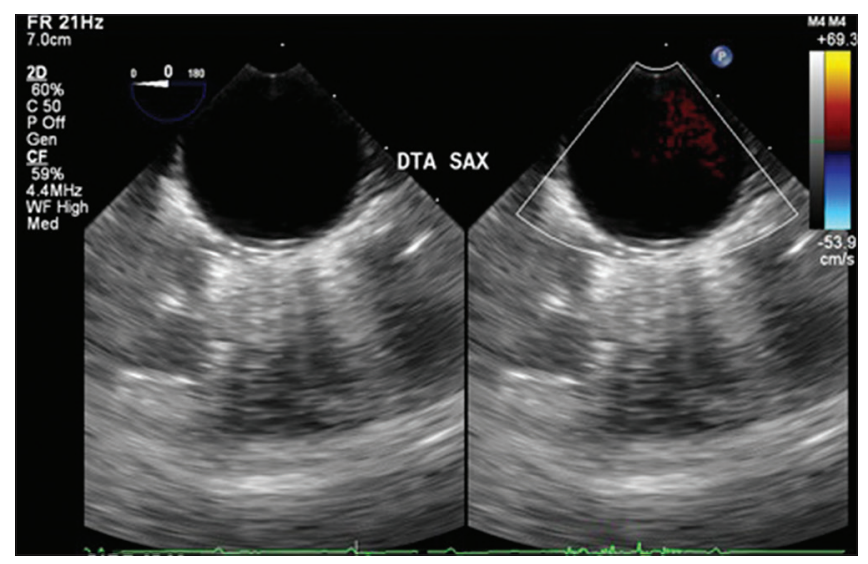

Figure 11: Upper oesophageal descending aortic short axis view

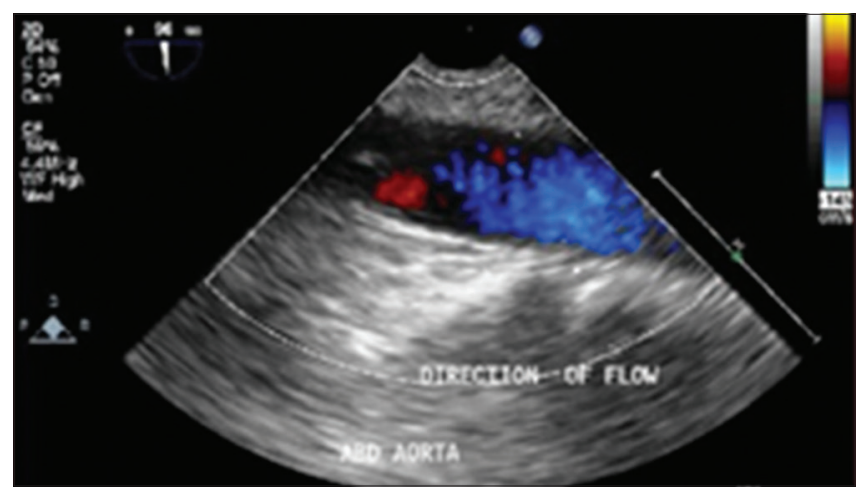

Figure 12: Upper oesophageal Descending aortic long view

the probe is not easy, a laryngoscope may be used to expose the posterior pharynx and permit direct passage of the probe into the esophagus. Avoid undue force at any stage during insertion of the probe

- The tip of the transducer is allowed to return to the neutral position before advancing or withdrawing the probe

- Clean and decontaminate of the probe after each use
- It is ideal to have an electrocardiogram trace on the echocardiographic imaging screen.

Common problems encountered in neurosurgical patients that can be diagnosed by TEE

- Venous air embolism and paradoxical air embolism

- Identification of haemodynamic instability during perioperative period

- Presence of associated cardiac anomaly with meningomyelocoele

- Cardiac manifestation of intracranial haemorrhage

- Positioning of ventriculo atrial (VA) shunt and identification of the complications related to it

- Positioning of RA aspiration catheter

- Percutaneous placement of VA shunt.

\section{Venous air embolism and paradoxical air embolism}

The advantages of sitting and semi-sitting positions during neurosurgical procedures are well-known. However, these positions are not free from dreaded risks like high-grade air embolism and subsequent central nervous dysfunction. The incidence of VAE ranges from $1.6-76 \%$ depending on the presence or absence of an intracardiac shunt and surgery in sitting/semi-sitting position. ${ }^{[4-8]}$ Preoperative examination by TTE with a valsalva maneuver and intravenous echo contrast can help to diagnose only the presence of an intracardiac shunt with $100 \%$ sensitivity does not add to the management of a case in which VAE occur. ${ }^{[9]}$ Demonstration of air bubbles in the great veins and cardiac chambers by TEE has to be considered as a warning sign of VAE. Once there is suspicion, necessary steps like interruption of surgical dissection and quick closure of venous system leak has to be followed. American Society of Anesthesiologists and Society of Cardiovascular Anaesthesiologists Task Force on TEE practice guidelines considers use of TEE as an class I indication to identify VAE during intraperative period. ${ }^{[1]}$

\section{Identification of the presence of intracardiac shunt} by TEE, Bubble contrast study

To know the presence of a patent foramen ovale (PFO)/atrial septal defect (ASD), a standard 2-D TEE view with special emphasis on the intra-atrial septum from midesophageal 4-chamber and bicaval view can be taken and windows that best displayed the intraatrial septum with LA and RA can be selected. [Figures 13 and 14] Agitated saline can be injected from a central line. This results in prompt opacification of RA and RV. In the presence of a intracardiac shunt, the left chambers also demonstrates the appearance of the micro bubbles. [Figure 15] 


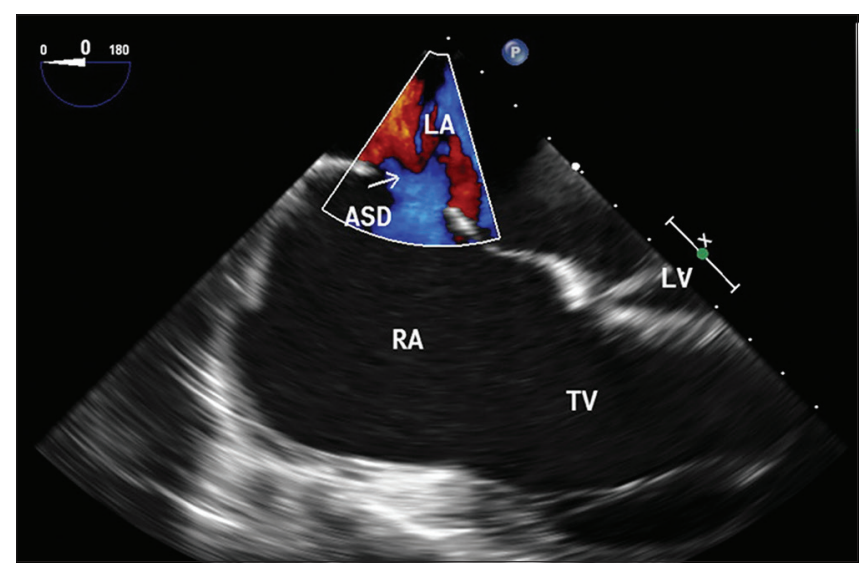

Figure 13: Mid oesophageal 4-chamber view showing atrial septal defect

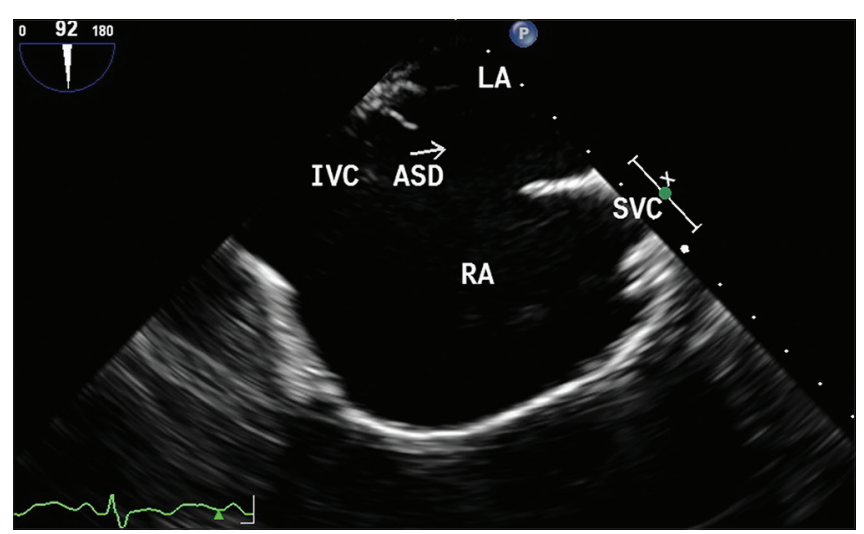

Figure 14: Mid oesophageal bicaval view showing atrial septal defect

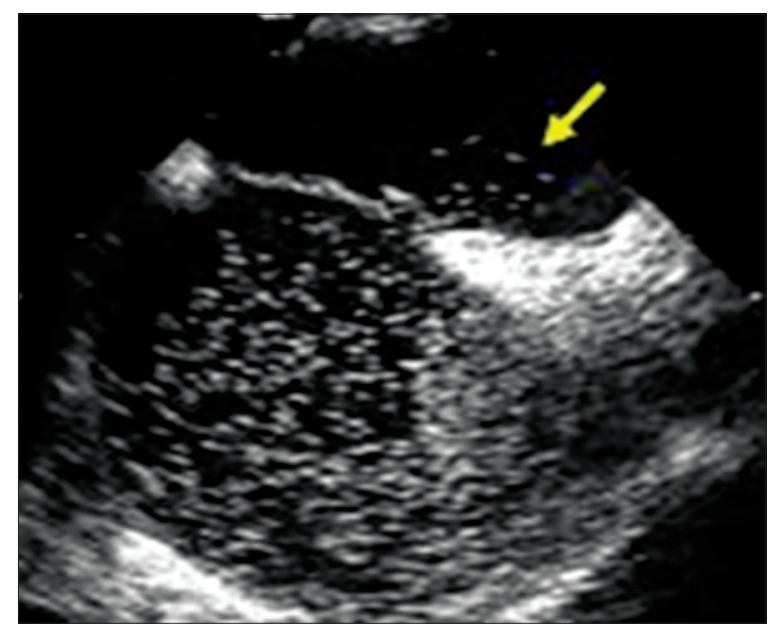

Figure 15: Bubble contrast (agitated saline) study to demonstrate $\mathrm{PFO}$, bubbles crossing interatrial septum and appears in LA

\section{TEE criteria for diagnosis of VAE}

Grade 0: No air bubble visible, no air embolism

Grade 1: Air bubble visible in TEE

Grade 2: Air bubble visible in TEE with decrease in end tidal carbon dioxide $\left(\mathrm{EtCO}_{2}\right) \leq 3 \mathrm{~mm} \mathrm{Hg}$

Grade 3: Air bubble visible in TEE with decrease in $\mathrm{EtCO}_{2}>3 \mathrm{~mm} \mathrm{Hg}$
Grade 4: Air bubble visible in TEE with decrease in $\mathrm{EtCO}_{2}>3 \mathrm{~mm} \mathrm{Hg}$ and decrease in mean arterial pressure $\geq 20 \%$ or increase in heart rate $>40 \%$ or both

Grade 5: Air embolism causing arrhythmia with haemodynamic instability requiring cardiopulmonary resuscitation. ${ }^{[9]}$

Every time, the appearance of air bubble on TEE even in patients with intracardiac shunt does not result in right to left shunting of air bubbles causing fatality. However, uses of TEE in semi-sitting position diagnose the clinically relevant events secondary to the presence of air in venous system e.g. a decrease in $\mathrm{EtCO}_{2}$ in capnography. ${ }^{[10,11]}$

Fathi et al. reviewed 4,806 patients considered for neurosurgery in sitting position and 5,416 patients who underwent percutaneous patent foramen ovale (PFO) closure. The overall rate of venous air embolism was 14-39\% and the rate of clinical and TEE defected paradoxical air embolism (PAE) was $0-14 \%$ in their series. The authors recommended screening of PFO and considering closure in cases in which the sitting position is the preferred neurosurgical approach. This study however has a major limitation due to lack of level 4 evidence and from using data from observational cohort studies. ${ }^{[5]}$ Three more authors identified TEE as a more sensitive method to diagnose VAE and PAE than transcranial Doppler (TCD). ${ }^{[12-14]}$

Two types of air embolism can be detected in 2-D TEE. The single bubble type, can happen during skin and muscle incisions, craniotomy and brain lesion excision. Electrocoagulation and application of bone wax can prevent further aggravation and embolism formation. The other one is stormy bubble type, which can happen during dura and muscle incision. This is prevented by electrocoagulation, reflection of the dura and suturing of the affected muscle. ${ }^{[15]}$

\section{Identification of associated cardiac anomaly and its relevance}

Meningomyelocoele is one of the common problems encountered in neonate. Conotruncal anomaly, septal defects, coartation of aorta, hypoplastic left heart syndrome apart from patent ductus arteriosus and PFO can be associated with Meningomyelocoele and have anaesthetic implications. In a series of 105 neonates aged from 1-20 days who were posted for Meningomyelocoele surgery, congenital heart disease was detected in $39 \%$ of patients in preoperative TEE examination. However, the cardiac examination was abnormal only in $13 \%$ cases. This report implies that as clinical examination to detect heart disease is insensitive in neonates, routine screening echocardiogram has an important implications for intracardiac shunting, 
urinary tract instrumentation (antibiotic prophylaxis), post-operative pulmonary hypertension and neurosurgical procedure (venous air embolism). ${ }^{[16,17]}$

\section{Utility of TEE for identification of cardiovascular instability in the operating room and ICU}

Cardiac manifestations of intracranial haemorrhage are an accepted phenomenon that affect in patient outcomes and poses a challenge for neuro-intensivists. The cardiac manifestations may vary from subtle electrocardiography (ECG) changes to myocardial infarction, congestive cardiac failure and ventricular dysfunction and Takatsubo cardiomyopathy. Takatsubo cardiomyopathy is one such condition which has a similar clinical picture like acute coronary syndrome (ACS) and distinguished from above by echocardiography findings. The treatment of Takatsubo cardiomyopathy is conservative whereas the later needs aggressive therapy including surgical intervention. The TEE finding of Takatsubo cardiomyopathy includes low ejection fraction, akinesia of mid and apical segments of left ventricle with or without a thrombus. ${ }^{[18-21]}$

Aneurysmal subarachnoid haemorrhage often present with haemodynamic instability and pulmonary oedema requiring vasoactive drugs. ${ }^{[22]}$ This situation is associated with severe ventricular dysfunction. There may be chamber dilation depending upon the duration of problem, regional wall motion abnormalities, global reduction in systolic function and decrease in ejection fraction (EF). ${ }^{[23]}$ Global reduction in systolic function is estimated from fractional area change (FAC), which is the proportional change in the area of left ventricle (LV) short axis (TG LVSX view) during systole and calculated from the following formula:

$$
\mathrm{FAC}=\frac{\mathrm{EDA}-\mathrm{ESA}}{\mathrm{EDA}} \times 100
$$

Where EDA = end diastolic area and ESA = end systolic area and the normal range is $36-64 \%$. EF represents the proportion of diastolic volume that is ejected during ventricular contraction and is calculated as:

$$
\mathrm{EF}=\frac{\mathrm{EDV}-\mathrm{ESV}}{\mathrm{EDV}} \times 100
$$

Where ESV = end systolic volume, EDV = end diastolic volume and the normal range is $55-75 \%$. $^{[24]}$

Neurogenic stunned myocardium presenting with left ventricle non-compaction can also occur in consequence to hypertensive hydrocephalous. This condition is associated with severe ventricular dysfunction and life-threatening ventricular ectopics during intraoperative period. ${ }^{[25]}$ TEE can demonstrate transient non-compaction aspect of the left ventricular wall.
In a normal person trabeculation of the ventricle is normal, as prominent, discrete muscular bundle $>2 \mathrm{~mm}$. In non-compaction, there is extremely prominent trabeculation. Echocardiographically, it is diagnosed when trabeculations are more than twice the thickness of the underlying ventricular wall. ${ }^{[26]}$ Timely diagnosis and treatment can save the patient.

Cardiovascular collapse can occur during spinal surgery due to acute blood loss following major vascular injury. At times, the bleeding is occult, when it is into the abdomen or retroperitoneum. ${ }^{[27,28]}$ This condition can be easily identified by TEE, the details are described elsewhere in this review. Myocardial ischaemia as a cause of severe haemodynamic disturbances associated with ST segment abnormality can occur during aneurysm clipping. ${ }^{[29]}$ As several other conditions are also responsible for ST segment changes, myocardial ischemia can be identified by appearance of new regional wall motion abnormalities (RWMA) in TEE (TG LV SX view) during continuous monitoring. TEE can also act as an ischaemia monitor when ECG is not interpretable (e.g. Bundle branch block or the presence of pace maker). ${ }^{[1]}$

Pericardial tamponade and heart failure can occur secondary to ventriculo-pleural shunt mal function. ${ }^{[30,31]}$ TEE findings in tamponade vary with rapidity of fluid collection in the pericardial space. The most important 2-D TEE finding is right ventricular collapse during diastole. There may be right atrial invasination during late diastole. Collection of fluid/blood can be identified in the pericardial cavity. ${ }^{[3]}$ Pulmonary embolism (PE) is a frequent cause of morbidity and mortality in neurosurgical practice. ${ }^{[32]}$ Pulmonary angiography is a gold standard to identify such situation. However, TEE is a rapid bed side test that is both sensitive and specific. The diagnosis of PE by TEE is often indirect. It is very uncommon to visualize a thrombus unless it is in the main pulmonary artery or proximal aspects of right or left pulmonary artery as rest of the segments are usually not visualized by TEE. In ICU patients, the identification of new onset of RV dysfunction should raise the possibility of $\mathrm{PE}$. There may be increased in size of pulmonary arteries, right ventricular dysfunction of varying degrees, flattening of interventricular septum, volume overload of RV, dilation of right atrium (RA), functional tricuspid regurgitation and increase in size of inferior venacava. ${ }^{[3]}$ In the absence of these findings the diagnosis of PE is unlikely. Initiation of thrombolytic therapy can be done if not contraindicated and patient could be followed up with another TEE examination, which can evaluate the efficacy of treatment as well.

Severe haemodynamic instability can happen due to inadequate volume status during the perioperative period. This has many causes apart from the neurosurgical problem and represents considerable threat to the life of 
the patient. TEE is ideal to identify the problem and guide appropriate therapy both in the operating room and intensive care unit. [Table 4] $]^{[24,33]}$

TEE guided volume management can be done with assessment of preload, contractility and afterload.

Preload: A number of ways have been proposed to assess LV volume by 2-D TEE. They can be used to do one-time assessment/continuous monitoring method to assess fluid responsiveness. The various measures are left ventricular end diastolic volume (LVEDV), left ventricular end diastolic area (LVEDA), superior venacava (SVC) collapsibility, inferior venacava (IVC) size and response to fluid challenge. ${ }^{[1,3]}$ The criteria for diagnosing hypovolemia include LV end diastolic diameter (LVEDD) less than $25 \mathrm{~mm}$, systolic obliteration of LV cavity (kissing papillary muscle) and a LV end diastolic area (LVEDA) of less than $55 \mathrm{~cm}^{2}$. These measures are obtained from the TG mid-papillay SX view of LV. ${ }^{[3]}$ LVEDA measurements have been validated to track the fluid status changes. Within the limits, fluid administration results in an increase in EDA; this is associated with an increase in stroke volume in case of hypovolemia.

Contractility: The usual methods used for the measurement for global LV systolic function are EF, FAC and segmental wall motion abnormality. Assessment of ventricular systolic function and their changes over time is of enormous help in therapeutic decision making (e.g. RWMA can indicate acute ischaemia where as RV dysfunction points more towards the presence of PE or COPD).

Afterload: It is estimated to be low when there is low mean arterial pressure, normal left ventricular end diastolic diameter (LVEDD) and collapsing LV at end systole as demonstrated by 2-D TEE.

Reduced LV compliance is associated with significant diastolic dysfunction have important implication for volume status. Firstly, EDA at which the LV is optimally filled will be low; and secondly, the required filling pressure will be high. Low systemic vascular resistance (SVR) often follows after significant blood loss, and a consequence of drug therapy. Sepsis is another reason for low SVR in patients with long-term ICU stay. The patients with low SVR often respond to an inotrope like nor epinephrine or phenylephrine when haemoglobin and volume status is adequate. LV systolic dysfunction is usually secondary to Takatsubo cardiomyopathy associated with normal left ventricular internal dimension but depressed LV ejection fraction. These patients usually respond to a negative inotrope (beta blocker), fluids and intra-aortic balloon pump. Chronic LV dysfunction is rare in neurosurgical setting unless the patient have a long standing history of myocardial infarction/cardiomyopathy. These patients have features of reduction in global LV function and ventricular dilatation along with a normal cardiac output and systemic blood pressure and are more susceptible to hypovolemia during the perioperative period. Acute systolic dysfunction also occur secondary to ischaemia following prolonged hypotension due to massive volume loss. These patients do not have any ventricular dilation, whereas systemic blood pressure and cardiac output may be severely depressed. Such patients are at high risk of haemodynamic instability during perioperative period and usually respond to volume and inotropes.

Placement of a ventriculoatrial shunt (VA shunt) is one of the commonest neurosurgical procedure for the treatment of hydrocephalus. Current positioning of the distal end of catheter in RA is of paramount importance for monitoring shunt patency and reducing the incidence of VA shunt related morbidity. TEE is a helpful aid to guide the placement of this shunt, advancement of guidewire and shunt catheter to SVC can be guided by TEE. ${ }^{[34,35]}$ This procedure is however not free from complications like thrombosis of intracardiac end of catheter, thromboembolism and tricuspid stenosis. Routine echocardiography at regular intervals can diagnose this problem and prevent the subsequent sequel to thromboembolism and tricuspid stenosis. ${ }^{[36,37]}$ TEE can also offer a rapid and accurate assessment of VA shunt function especially detection of a leak of cerebrospinal fluid to RA through the shunting device. ${ }^{[38]}$ Tonn reported a case of bilateral basal infiltrate and pleural effusion in a patient with VA shunt. TEE established the diagnosis of a thrombus

Table 4: TEE findings of some common haemodynamic problem

\begin{tabular}{|c|c|c|c|c|c|c|c|}
\hline \multirow[t]{2}{*}{ Problem } & \multicolumn{4}{|c|}{ TEE finding } & \multicolumn{3}{|c|}{ Haemodynamic findings } \\
\hline & Contractility & EDA & ESA & FAC & BP & CI & RAP \\
\hline Hypovolemia & Vigorous & $\downarrow$ & $\downarrow$ & $\leftrightarrow$ & $\downarrow$ & $\downarrow$ & $\downarrow$ \\
\hline Reduced LV compliance & Vigorous & $\downarrow$ & $\downarrow$ & $\leftrightarrow$ & $\downarrow$ & $\downarrow$ & $\leftrightarrow$ \\
\hline Low SVR & Vigorous & $\leftrightarrow$ & $\downarrow$ & $\uparrow$ & $\downarrow$ & $\uparrow$ & $\uparrow$ \\
\hline Systolic Dysfunction & Vigorous & $\uparrow$ & $\uparrow$ & $\downarrow$ & $\downarrow$ & $\downarrow$ & $\uparrow$ \\
\hline
\end{tabular}

EDA: End diastolic area, ESA: End systolic area, FAC: Fractional area change, Cl: Cardiac index, RAP: Right atrial pressure, LV: Left ventricle, SVR: Systemic vascular resistance, BP: Blood pressure, TEE: Transoesophageal echocardiography 
in right atrium which was removed and a shunt revision was performed. ${ }^{[39]}$ Percutaneous approach of placement of VA shunt is gaining importance to make the procedure less invasive there by a reduced hospital length of stay and less complication. TEE can monitor the exact position of atrial catheter tip and its function. ${ }^{[40]}$ Hydatid cyst of brain though uncommon is not a rare entity. This may associated with a cyst in heart which can be diagnosed by echocardiography in the same setting. A timely diagnosis can prevent the cardiac complications. ${ }^{[41]}$

\section{Future direction}

There is no randomized clinical trials evaluating the impact of TEE in neurosurgical and neuroanaesthesia settings An ideal trial in this area can be done which may show the beneficial effect of the change in TEE directed problem management and initiation of various anti ischemic and thrombolytic measures apart from guided volume therapy on the post-operative outcome compared to the current standard monitors. TEE is a monitor that can change the process of perioperative management in neurosurgical patients but may not change the surgery per se. This technology should be compared with other routine monitors (pulmonary artery catheter and non-invasive cardiac output monitor) to evaluate the reliability, interpretability and change in decision making which has a direct effect on the patient outcome in terms of hospital length of stay, decrease in post-operative morbidity and mortality. One can go for cost-effective and cost-effective analysis to make an effective impact in neuroanaesthesia practice.

\section{SUMMARY AND CONCLUSION}

TEE provides diagnostic and prognostic information and is increasingly important in guiding the surgeon as well as the anaesthesiologist for management of neurosurgical patients in the operating room as well as in ICU. It adopts a basic framework nearly similar to that for cardiac patients. This monitor is useful only if the information that it provides is of high quality and interpreted correctly. It is still a specialized form of monitoring in neuroanaesthesia set-up. Prophylaxis or early detection of the presence of PFO, occurrence of VAE or Takatsubo cardiomyopathy can save some patients. Refractory cases of haemodynamic instability, complications of VA shunt or post-operative pulmonary thromboembolism can be detected early with this aid. In conclusion, over time, with improvements in education, and affordable basic equipment, more neuroanaesthesiologist will utilize echocardiography. In future, perioperative echocardiography will be the new standard in monitoring as it becomes part of routine anaesthesia care.

\section{REFERENCES}

1. American Society of Anesthesiologists and Society of Cardiovascular Anesthesiologists Task Force on Transesophageal Echocardiography. Practice guidelines for perioperative transesophageal echocardiography. An updated report by the American society of anesthesiologists and the society of cardiovascular anesthesiologists task force on transesophageal echocardiography. Anesthesiology 2010;112:1084-96.

2. Shanewise JS, Cheung AT, Aronson S, Stewart WJ, Weiss RL, Mark JB, et al. ASE/SCA guidelines for performing a comprehensive intraoperative multiplane transesophageal echocardiography examination: Recommendations of the American society of echocardiography council for Intraoperative echocardiography and the society of cardiovascular anesthesiologists task force for certification in perioperative transesophageal echocardiography. Anesth Analg 1999;89:870-84.

3. Oh JK,Seward JB,Tajik AF.Transesophagealechocardiography. In: The Echo Manual. $2^{\text {nd }}$ ed. Philadelphia: Lippincott-Raven; 1999. p. 3-36.

4. Jadik S, Wissing H, Friedrich K, Beck J, Seifert V, Raabe A. A standardized protocol for the prevention of clinically relevant venous air embolism during neurosurgical interventions in the semi-sitting position. Neurosurgery 2009;64:533-8.

5. Fathi AR, Eshtehardi P, Meier B. Patent foramen ovale and neurosurgery in sitting position: A systematic review. $\mathrm{Br} \mathrm{J}$ Anaesth 2009;102:588-96.

6. Standefer M, Bay JW, Trusso R. The sitting position in neurosurgery: A retrospective analysis of 488 cases. Neurosurgery 1984;14:649-58.

7. Zuber M, Cuculi F, Oechslin E, Erne P, Jenni R. Is transesophageal echocardiography still necessary to exclude patent foramen ovale? Scand Cardiovasc J 2008;42:222-5.

8. Cucchiara RF, Bowers B. Air embolism in children undergoing suboccipital craniotomy. Anesthesiology 1982;57:338-9.

9. Feigl GC, Decker K, Wurms M, Krischek B, Ritz R, Unertl K, et al. Neurosurgical procedures in the semisitting position: Evaluation of the Risk of paradoxical venous air embolism in patients with a patent foramen ovale. World Neurosurg 2014;81:159-64.

10. Black S, Muzzi DA, Nishimura RA, Cucchiara RF. Preoperative and intraoperative echocardiography to detect right to left shunt in patients undergoing neurosurgical procedures in the sitting position. Anesthesiology 1990;72:436-8.

11. Cucchiara RF, Seward JB, Nishimura RA, Nugent M, Faust RJ. Identification of patent foramen ovale during sitting position craniotomy by transesophageal echocardiography with positive airway pressure. Anesthesiology 1985;53:107-9.

12. Mammoto T, Hayashi Y, Ohnishi Y, Kuro M. Incidence of venous and paradoxical air embolism in neurosurgical patients in semi sitting position: Detection by transesophageal echocardiography. Acta Anaesthesiol Scand 1998;42:643-7.

13. Caputi L, Carriero MR, Falcone C, Parati E, Piotti P, Materazzo C, et al.Transcranial Doppler and transesophageal echocardiography: Comparison of both techniques and prospective clinical relevance of transcranial Doppler in patent foramen ovale detection. J Stroke Cerebrovasc Dis 2009; 18:343-8.

14. Ganslandt O, Merkel A,Schmitt H,Tzabazis A, Buchfelder M, Eyupoglu I, et al. The sitting position in neurosurgery: Indications, complications and results. A single institution experience of 600 cases. Acta Neurochir (Wien) 2013;155:1887-93.

15. Sato S, Toya S, Mine T, Greig NH.Echocardiographicdetection 
and treatment of intraoperative air embolism. J Neurosurg 1986;64:440-4.

16. Belisario C, Generoso M, Brandigi L, Menci R, Merello G, Ammanati V. Extracardiac malformations in infants with congenital heart diseases: Clinical research and statistics covering period 1969-79 (author's transl). Pediatr Med Chir 1981;3:363-8.

17. Ritter S, Tani LY, Shaddy RE, Minich LL. Are screening echocardiograms warranted for neonates with meningomyelocele? Arch Pediatr Adolesc Med 1999;153:1264-6.

18. Di Pasquale G, Andreoli A, Lusa AM, Urbinati S, Biancoli S, Cerè E, et al. Cardiologic complications of subarachonoid hemorrhage. J Neurosurg Sci 1998;42:33-6.

19. Inamasu J, Nakatsukasa $M$, Mayanagi $K$, Miyatake $S$, Sugimoto K, Hayashi T, et al. Subarachonoid hemorrhage complicated with pulmonary edema and takotsubo like cardiomyopathy. Neurol Med Chir (Tokyo) 2012;52:49-55.

20. Yokota H, Sugiura S, Ida Y, Itoh H. Neurogenic stress cardiomyopathy following aneurysmal subarachonoid hemorrhage in a very elderly patient - Case report. Neurol Med Chir (Tokyo) 2011;51:842-6.

21. Citro R, Piscione F, Parodi G, Salerno-Uriarte J, Bossone E. Role of echocardiography in takotsubo cardiomyopathy. Heart Fail Clin 2013;9:157-66.

22. McLaughlin N, Bojanowski MW, Denault A. Early myocardial dysfunction following subarachnoid hemorrhage. $\mathrm{Br} J$ Neurosurg 2005;19:141-7.

23. Skiles JA,Griffin BP.Transesophageal echocardiographic (TEE) evaluation of ventricular function. Cardiol Clin 2000;18:681-97.

24. Weiss SJ, Augoustides JG. Transesophageal echocardiography for coronary revascularization. In: A Practial approach to Transesophageal echocardiography. By Perrino AC, Leeves ST. $2^{\text {nd }}$ ed. Philadelphia: Lippincott, Williams and Wilkins. p. 298-318.

25. De Rosa G, Pardeo M, Di Rocco C, Pietrini D, Mensi S, Stival E, et al. Neurogenic stunned myocardium presenting as left ventricular hypertrabeculation in childhood: A variant of Takotsubo cardiomyopathy. Pediatr Crit Care Med 2011;12:e420-3.

26. Cheng TO. Left ventricular noncompaction cardiomyopathy: Three decades of progress. Int J Cardiol 2014;174:227-9.

27. Prabhakar H, Bithal PK, Dash M, Chaturvedi A. Rupture of aorta and inferior vena cava during lumbar disc surgery. Acta Neurochir (Wien) 2005;147:327-9.

28. Dosoglu M, Is M, Pehlivan M, Yildiz KH. Night mares in lumbar disc surgery: Iliac artery injury. Clin Neurol Neurosurg 2006;108:174-7.

29. Kotake Y, Matsumot M, Yorozu T, Takeda J. Recurrent
ST-segment elevation on ECG and ventricular tachycardia during neurosurgical anesthesia. J Anesth 2009;23:115-8.

30. Zaman M, Akram H, Hallasos N, Bavetta S. Cardiac tamponade and heart failure secondary to venticulopleural shunt mal function: A rare presentation. BMJ Case Rep 2011;2011:bcr1220092548.

31. Jorro Baron F, Casanovas A, Guaita E, Bolasell C, Rombola V, Debaisi G. Cardiac tamponade as a complication of ventriculo atrial shunt. Arch Argent Pediatr 2012;110:e1-3.

32. Erbengl A, Berkar M. Pulmonary embolism in neurosurgical patients. Surg Neurol 1996;43:123-9.

33. Schober P, Loer SA, Schwarte LA. Perioperative monitoring with transesophageal Doppler technology. Anesth Analg 2009;109:340-53.

34. Raftopoulos C, Vandestene A. Ventriculoatrial shunt distal catheter placement using transesophageal echocardiography: Technical note. Neurosurgery 1992;31:1136.

35. Machinis TG, Fountas KN, Hudson J, Robinson JS, Troup EC. Accurate placement of distal end of a ventriculoatrial shunt with the aid of transesophageal echocardiography: Technical note. J Neurosurg 2006;105:153-6.

36. Mujanvic E, Bergsland J, Jurcic $S$, Avdic $S$, Stanimirovic-Mujanovic S, Kabil E. Calcified right atrial and pulmonary artery mass after ventriculoatrial shunt insertion. Med Arh 2011;65:363-4.

37. Akram Q, Saravanan D, Levy R. Valvuloplasty for tricuspid stenosis caused by a ventriculoatrial shunt. Catheter Cardiovasc Interv 2011;77:722-5.

38. Calliav L, Vandenbogaerge J, Kalala O, Caemaert J, Martens F, Vandekerchhove T. Transesophageal echocardiography: A simple method for monitoring the patency of ventricular shunts. Technical note. J Neurosurg 1991;74:1018-20.

39. Tonn P, Gilsbach JM, Kreitschmann-Andermahr I, Franke A, Blindt R. A rare but life threatening complication of ventriculo-atrial shunt. Acta Neurochir (Wien) 2005;147:1303-4.

40. Chuang HL, Chang CN, Hsu JC. Minimally invasive procedure for ventriculoatrial shunt combining a percutaneous approach with real time transesophageal echocardiogram monitoring: Report of six cases. Chang Gung Med J 2002;25:62-6.

41. Karabay O, Onen A, Yildiz F, Yilmaz E, Erdal CA, Sanli A, et al. The case of cyst hydatid localized within the interatrial septum. Jpn Heart J 2004;45:703-7.

How to cite this article: Choudhury M. Transoesophageal echocardiography: What a neuroanaesthesiologist should know?. J Neuroanaesthesiol Crit Care 2015;2:3-14.

Source of Support: Nil, Conflict of Interest: None declared. 